\title{
Cervical cancer analysis: From burden to treatment
}

\author{
Disha Tiwari', Kirti Srivastava², Dewesh Kishan ${ }^{3}$, Manjari Shah $^{4}$ \\ 1,3Senior Resident,Department of Radiation Oncology, Delhi State Cancer Institute, Delhi, India, ${ }^{2}$ Professor, Department \\ of Radiation Oncology, King George's Medical University, Lucknow, Uttar Pradesh, India, ${ }^{4}$ Senior Resident, Department \\ Of Radiation Oncology, Jaypee Hospital, Noida, Delhi-NCR, India
}

Background: Cancer has emerged as huge epidemic over past two decades. There is a declining trend in the incidence of cervical cancer in the western world on the contrary in India we have observed that this disease is a great menace to a women's health and is showing rising trend. Within the country there is wide range of variation in demography and epidemiology. There is lack of published data available on epidemiology such as age, incidence, burden, compliance of patients having cervical cancer in Uttar Pradesh. Aims and Objectives: Current study aims to gather the evidence to understand the pattern of cervical cancer burden in the community and to find out the lacunae in the treatment delivery and receiving end. Materials and Methods: A retrospective study was conducted on patients of cancer cervix visiting OPD of department of radiation oncology. The study comprised retrieval of medical records for different variables like age, stage, district etc and analysing it to understand the presentation and burden of disease. Results: A total of 470 patients were studied for their epidemiology. Majority of patients were from Lucknow (78) and its nearby districts. Out of 75 districts of Uttar Pradesh, patients from 38 different districts had come to seek radiation treatment which is almost half of the Uttar Pradesh. Majority of patients in study were women in their $5^{\text {th }} \& 6^{\text {th }}$ decade. The most common stage of diagnosis was II $\mathrm{B}$. On histopathological evaluation most common variant found was squamous cell carcinoma with moderate differentiation $26.38 \%$. Conclusion: Our study highlights lack of resources in Uttar Pradesh as patients had travelled from peripheral districts to seek treatment, which lead to frequent treatment breaks and poor compliance for follow up.

Key words: Cervical Cancer; Prevalence; Epidemiology DOI: 10.3126/ajms.v10i1.21058 E-ISSN: 2091-0576 P-ISSN: 2467-9100

\section{INTRODUCTION}

Cancer has emerged as huge epidemic over past two decades. ${ }^{1}$ In the province of cancer, cervical cancer has hegemony among women of low socio-economic background especially in developing countries like India. ${ }^{2}$ There is a declining trend in the incidence of cervical cancer in the western world on the contrary in India we have observed that this disease is a great menace to a women's health and is showing rising trend. As per Ferlay $\mathrm{J}$ et $\mathrm{al}^{3}$ a woman's cumulative risk of developing cervical cancer by age 74 is $0.9 \%$ in developed countries compared to $1.9 \%$ in developing countries. As per population based registries from 2012-2014 in National Cancer Registry Programme(NCRP). ${ }^{4}$ incidence of cervical cancer holds top position among females of rural area and it is the second most common cancer among urban females. The GLOBOCAN $2012^{5}$ report for India for cervix uteri cancer reveals an estimated 123,000 new cases and 67,000 deaths.Indian Council of Medical Research(ICMR) has prophecy about cervical that it will be the second most common gynecological malignancy with the estimated $1,23,291$ new cases by $2020 .{ }^{6}$ As per SEER data the median age of diagnosis is 49 years and whereas in India the peak age for cervical cancer incidence is $55-59$ years. 
Cervical cancer is almost always associated with human papilloma virus infection [HPV]. The development of carcinoma cervix is a multistep process initiated by persistent infection with high-risk HPV, which in a limited number of cases progresses via cervical intraepithelial neoplasia to invasive cervical cancer. ${ }^{8}$

Cervical cancer arises most commonly from squamous epithelial cells of uterine cervix (squamous cell carcinoma) or glandular epithelial cells of endocervix (adenocarcinoma). These two types make up around $90 \%$ of cases of cervical cancer and squamous is the most common about $80 \%$ cases.

Human papilloma virus is the single most cause of invasive cervical cancers and the most common strains which women of cancer cervix harbours are HPV16 and HPV18.

HPV infection is seen in sexually active women and mostly it resolves by itself without causing obvious signs of disease but changes may be evident in cervical smears. However, in few women, infection persists and may progress to invasive cervical cancer. This progression generally takes many years so this forms the basis of cervical cancer screening.

In western world, the incidence of adenocarcinoma is rising as compared to squamous cell carcinoma because of extensive cervical cancer screening program as adenocarcinoma is liable to get missed on screening.

On retrospective analysis we found out the two main reasons which unfolds the baffling mystery of rising trend in our part of world are lack of awareness and education especially in women of low socio economic strata. As issues related to sex and diseases transmitted via this way like human papilloma virus, is still a taboo in India as it is difficult to educate and motivate masses for screening. Apart from cancer awareness campaigns, the screening facilities are yet not available for rural populations. On account of above mentioned reasons, the majority of rural females present with advanced disease. In developing countries like India, facing major problem of cervical cancer related death is because we are lacking in widespread use of vaccines and implementation of screening programs in peripheral hospitals too. Government and health professionals together in collaboration have to mend their ways to bridge this huge gap.Mass education is required to get the breakthrough.

Within the country there is wide range of variation in demography and epidemiology. There is lack of published data available on epidemiology such as age, incidence, burden, compliance of patients having cervical cancer in Uttar Pradesh. In this retrospective analysis we have tried to gather the evidence to understand the pattern of cervical cancer burden in the community.

\section{MATERIALS AND METHODS}

This study was carried out in Department of Radiotherapy, KGMU, Lucknow, a tertiary care center, which provide cancer diagnosis and treatment facility to not only people of Uttar Pradesh but also to neighbor states like Bihar and country like Nepal. This study was conducted for the period of January 2013 to December 2015. Medical records of included patients were retrieved and data was gathered for different variables like age, histopathology, stage, operative details, treatment taken and follow-up. Keeping in view that many patient default after undergoing full course of treatment we have tried to obtain their status via telephone. Data were entered and analyzed by using SPSS21.0.

\section{Ethical considerations}

This study was conducted after approval from Institutional Ethics Committee of King George's Medical University, Lucknow.

\section{RESULTS}

A total number of 11,068 patients were registered in Department of Radiotherapy from January 2013 till December 2015 as shown in Table-1. Out of these $1678(15 \%)$ patients were registered as cancer cervix in different units of department of radiotherapy. To rule out any heterogeneity in treatment policy prevailing in different units we have chosen single unit for our study purpose.

A total of 470 patients were studied for their epidemiology. In our study we found that majority of patients were from Lucknow (78) and its nearby districts like Sitapur (40), Hardoi (31) and Barabanki (30) as shown in Figure-1. Out

\begin{tabular}{|c|c|c|c|c|c|c|c|}
\hline \multirow[t]{2}{*}{ Year } & \multirow[t]{2}{*}{ Cervix registration } & \multirow[t]{2}{*}{ Total registration } & \multirow[t]{2}{*}{$\%$} & \multicolumn{4}{|c|}{ Number of patients audited } \\
\hline & & & & Definitive & Post-Op & Palliative/metastatic & Total \\
\hline 2013 & 606 & 3724 & 16.27 & 87 & 35 & 09 & 131 \\
\hline 2014 & 573 & 3712 & 15.40 & 112 & 35 & 11 & 158 \\
\hline 2015 & 499 & 3632 & 13.70 & 124 & 51 & 06 & 181 \\
\hline
\end{tabular}


of 75 districts of Uttar Pradesh, patients from 38 different districts had come to seek radiation treatment which is almost half of the Uttar Pradesh. Patients also had come from other states like Bihar and Chhattisgarh. Study population also include patient from neighbor country like Nepal.

Majority of patients in study were women in their $5^{\text {th }} \&$ $6^{\text {th }}$ decade. The most common stage of diagnosis was II B $(31.70 \%)$ followed by III B $(27.65 \%)$ as shown in Table-2.

For $28 \%$ of patients no information regarding stage was found. On further analysis of this subset, these were the patients who had received treatment at other centers and majority were post operated cases with no prior examination and surgical detail as they were operated in periphery.
On histopathological evaluation most common variant found was squamous cell carcinoma with moderate differentiation $26.38 \%$. Out of 470 patients 16 patients were registered as either palliative or metastatic cases. $323(69 \%)$ patients were registered with intact cervix and $131(28 \%)$ were as post operated cases. $31 \%$ of patients defaulted either after registration or during initial work up as shown in Table-3.

\section{DISCUSSION}

The present study was undertaken in an effort to find the pattern of cervical cancer burden coming to our institution, patient's compliance to treatment and follow-up and to understand the issues regarding lost to follow -up.

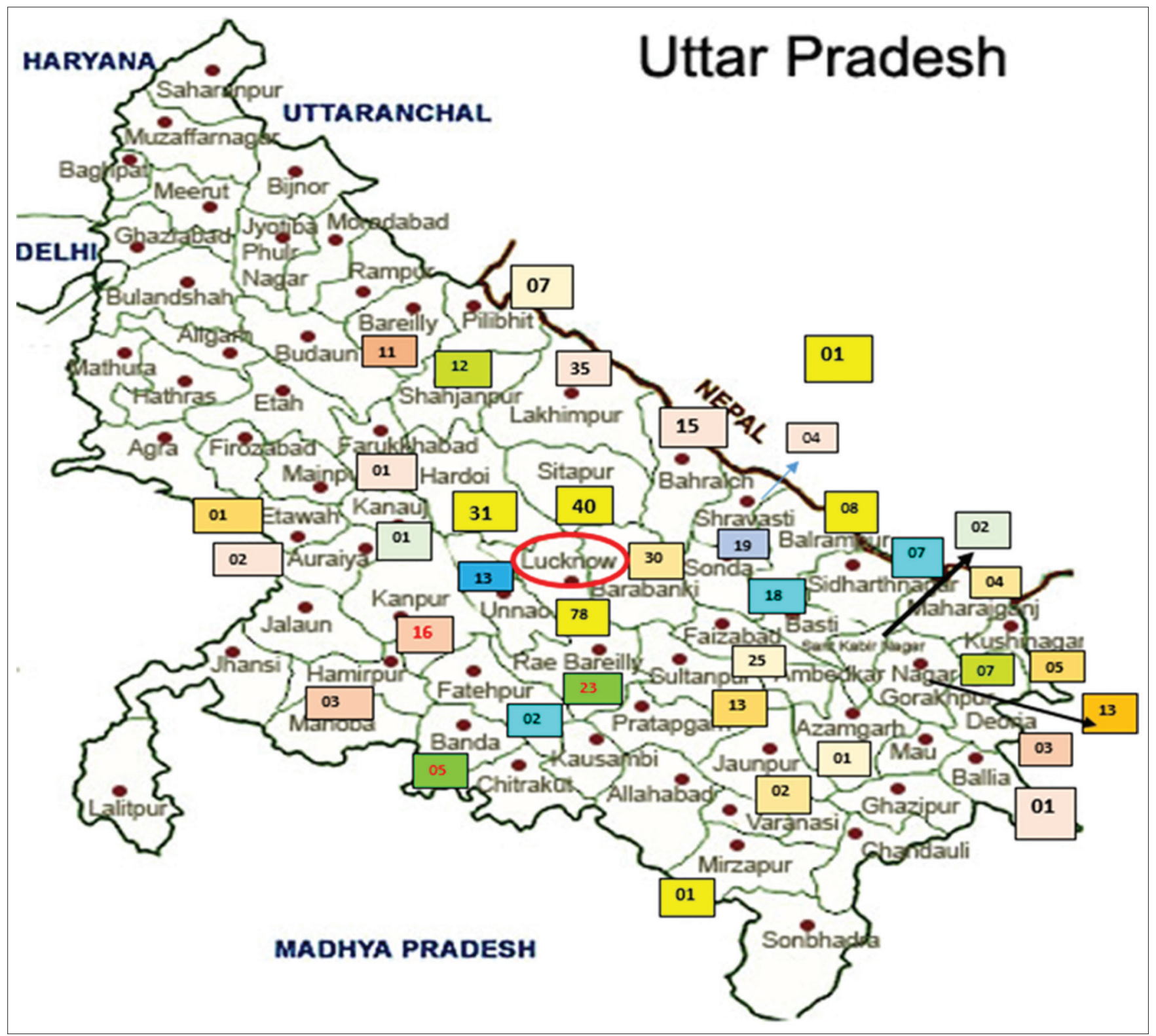

Figure 1: District- wise distribution of cervical cancer patients 


\begin{tabular}{|c|c|c|c|c|}
\hline Parameters & $2013(n=131)$ & $2014(n=158)$ & $2015(n=181)$ & $\%$ \\
\hline \multicolumn{5}{|l|}{ Age groups } \\
\hline$<30$ Years & 01 & 01 & 02 & 00.85 \\
\hline 30-40Years & 32 & 42 & 35 & 23.19 \\
\hline $41-50$ Years & 42 & 58 & 61 & 34.25 \\
\hline $51-60$ Years & 35 & 33 & 52 & 25.53 \\
\hline $61-70$ Years & 16 & 19 & 23 & 12.34 \\
\hline >70Years & 05 & 05 & 08 & 03.82 \\
\hline \multicolumn{5}{|l|}{ Stage } \\
\hline IB & 07 & 02 & 06 & 03.19 \\
\hline II A & 05 & 00 & 04 & 01.91 \\
\hline II B & 34 & 54 & 61 & 31.70 \\
\hline III A & 00 & 01 & 03 & 00.85 \\
\hline III B & 31 & 46 & 53 & 27.65 \\
\hline IV A & 07 & 09 & 08 & 05.16 \\
\hline IV B (Metastatic) & 01 & 05 & 02 & 01.70 \\
\hline Unknown & 46 & 41 & 43 & 27.65 \\
\hline \multicolumn{5}{|l|}{ Histopathology } \\
\hline SCC with unknown differentiation & 63 & 60 & 63 & 39.57 \\
\hline SCC well differentiated & 04 & 02 & 16 & 04.68 \\
\hline SCC moderately differentiated & 31 & 38 & 55 & 26.38 \\
\hline SCC poorly differentiated & 08 & 03 & 06 & 03.61 \\
\hline Adenocarcinoma & 07 & 10 & 08 & 05.31 \\
\hline Others & - & 05 & 32 & 07.87 \\
\hline Unknown histopathology & 18 & 40 & - & 12.34 \\
\hline \multicolumn{5}{|l|}{ Religion } \\
\hline Hindu & 121 & 141 & 168 & 91.48 \\
\hline Muslim & 10 & 07 & 13 & 06.38 \\
\hline Other & - & - & - & \\
\hline
\end{tabular}

\section{Table 3: Distribution on basis of treatment received}

\begin{tabular}{ccccc}
\hline & Single visit & Incomplete treatment & $\%$ & Complete treatment (EBRT+Brachytherapy) \\
\hline $\begin{array}{c}\text { Definitive } \\
N=323\end{array}$ & $97(30.03 \%)$ & 37 & 11.45 & $189(58.51 \%)$ \\
$\begin{array}{c}\text { Post-Op } \\
N=131\end{array}$ & $35(26.71 \%)$ & 31 & 23.66 & $55(41.98 \%)$ \\
\hline
\end{tabular}

The most common age group of presentation in our study is 41-60 years which is in accordance with national cancer registry program (NCRP). In a retrospective analysis of cancer cervix patients Saibishkumar et al ${ }^{10}$, they have reported most common stage of diagnosis as IIB and most common histopathology as squamous cell carcinoma followed by adenocarcinoma likewise in our study we have also found similar results for both stage and histopathology. In a study done in South India ${ }^{11}$ they have mentioned poor socioeconomic status as major impact factor in delay in diagnosis leading to advance stage of presentation. Study undertaken by Mandal and Roy ${ }^{12}$ reported poor compliance in patients of cancer cervix is due to financial constraints.

When we had analyzed our population to gather facts for poor compliance, major reasons that we can enumerate are financial issues as majority of our patients were from poor socio-economic background. Secondly we would like to emphasize that due to lack of transportation from periphery to our center, a large number of patient default at various steps of treatment. Thirdly lack of education and awareness in the family is a big social challenge which is knitting web like spider and taking toll on women life. Poor family support and other social responsibilities which women had to bear keeping her own health aside is the cause of advance presentation among rural population.

\section{CONCLUSION}

Our study highlights lack of resources in the peripheral district of Uttar Pradesh as patients had travelled from periphery to seek treatment to the capital, which lead to frequent treatment breaks and poor compliance for follow up. As majority of patients were diagnosed in their advanced stage, we would also like to highlight lack of implementation of screening programs in the community. There is massive lacunae present between prevention strategies and facility availed by the population. Education and awareness regarding vaccination and Pap test is the need of hour to fight this problem from its inception. This will decrease load on present health infrastructure. At 
last to conclude we require more hospital and population based registries to get the real picture and to improve our infrastructure accordingly. Integrated management approach is required to combat current Indian scenario of cancer cervix which include collaborated work from hospital based workers with community workers.

\section{REFERENCE}

1. Nandakumar A, Ramnath T and Chaturvedi M. The magnitude of cancer cervix in India. Indian J Med Res 2009; 130(3):219-221.

2. Denny L. Cervical cancer: prevention and treatment. Discov Med 2012; 14:125-131.

3. Ferlay J, Soerjomataram I, Dikshit R, Eser S, Mathers C, Rebelo $\mathrm{M}$, et al. Cancer incidence and mortality worldwide: Sources, methods and major patterns in GLOBOCAN 2012. International Journal of Cancer 2014; 136(5): E359-E386.

4. National Cancer Registry Programmme[Internet]. Ncrpindia.org. 2017. Available from: http://www.ncrpindia.org

5. Globocan 2012 - Home [Internet]. Globocan.iarc.fr. 2017 [cited 11 September 2017]. Available from: http://globocan.iarc.fr/ Default.aspx
6. Takiar R, Nadayil D and Nandakumar A. (2010). Projections of Number of Cancer Cases in India (2010-2020) by Cancer Groups. Asian Pac J Cancer Prev 2010;11(4):1045-1049.

7. World - both sexes estimated incidence by age. Available from: http://www. globocan.iarc.fr/old/age_ specific_table_r.asp? Accessed October 30, 2014.

8. Woodman CB, Collins SI and Young LS. The natural history of cervical HPV infection: unresolved issues. Nature Reviews Cancer 2007; 7:11-22.

9. Lax S. Histopathology of cervical precursorlesions and cancer. Acta Dermatovenerologica Alpina, Pannonica et Adriatica 2011; 20:125-133.

10. Saibishkumar E, Patel F, Sharma S, Karunanidhi G, Ghoshal S, Kumar $V$, et al. Prognostic value of response to external radiation in stage IIIB cancer cervix in predicting clinical outcomes: A retrospective analysis of 556 patients from India. Radiotherapy and Oncology 2006; 79(2);142-146.

11. Kaku M, Mathew A and Rajan B. Impact of socio-economic factors in delayed reporting and late-stage presentation among patients with cervix cancer in a major cancer hospital in South India. Asian Pac J Cancer Prev 2008; 9(4):589-594.

12. Mandal S and Roy K. Pattern of Compliance with Treatment and Follow-up of Cervical Cancer Patients at Chittaranjan National Cancer Institute, Calcutta. Asian Pac J Cancer Prev 2000;1(4):289-292.

Authors Contribution:

DT-Data collection, Manuscript, Editing, Review of literature; KS-Concept of study, Study design and Revision of manuscript; DK-Data collection and

Preparation of Draft; MS-Proof Reading and Revision of Manuscript.

Work attributed to:

Department Of Radiation Oncology, King George's Medical University, Lucknow, Uttar Pradesh, India

Orcid ID:

Dr Disha Tiwari - Dhttp://orcid.org/0000-0003-1262-9837

DrKirtiSrivastava - Dhttp://orcid.org/0000-0003-1262-3064

DrDeweshKishan - Dhttp://orcid.org/0000-0002-2233-9684

DrManjari Shah - http://orcid.org/0000-0001-9665-9624

Source of Support: Nil, Conflict of Interest: None 